Provided for non-commercial research and education use. Not for reproduction, distribution or commercial use.

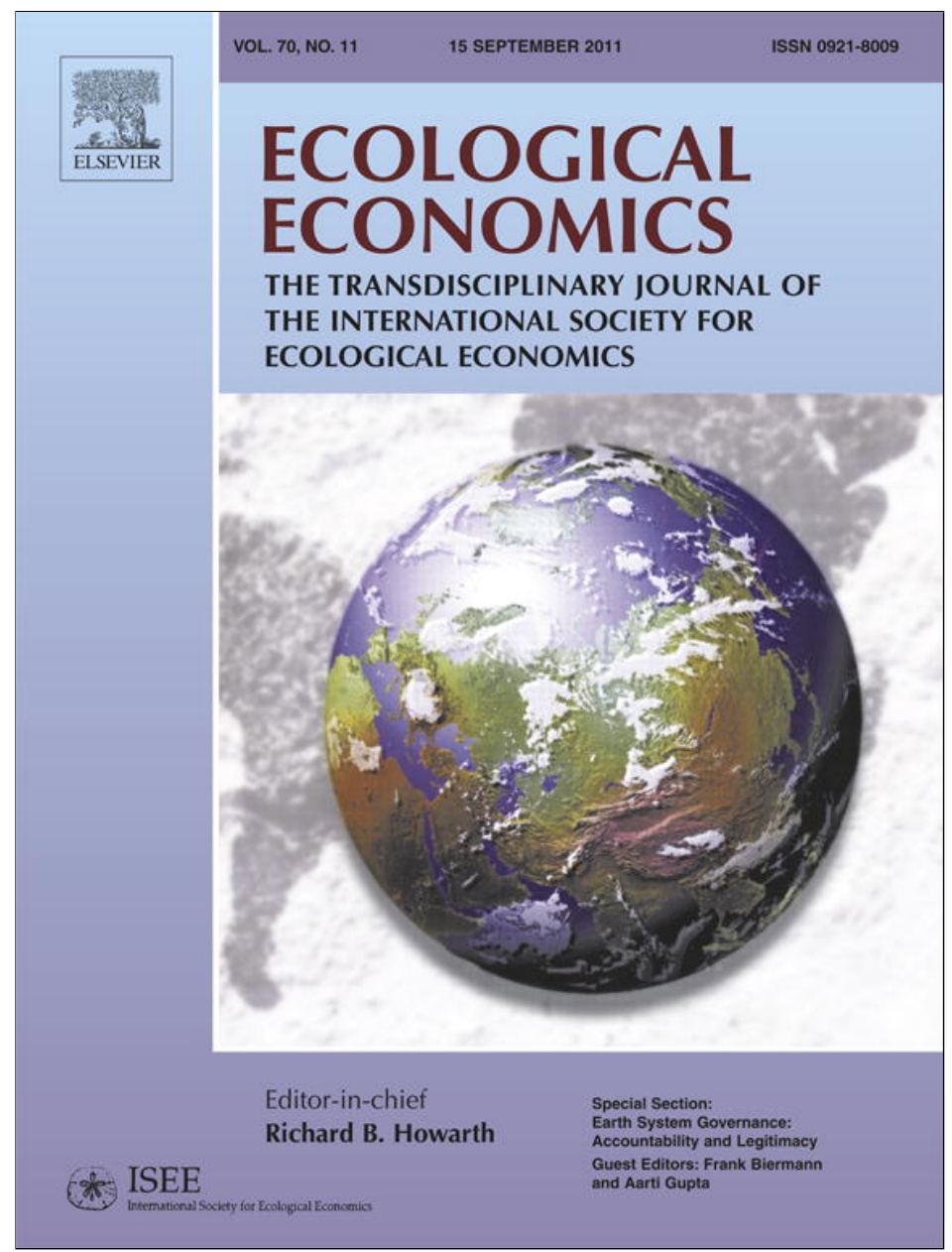

This article appeared in a journal published by Elsevier. The attached copy is furnished to the author for internal non-commercial research and education use, including for instruction at the authors institution and sharing with colleagues.

Other uses, including reproduction and distribution, or selling or licensing copies, or posting to personal, institutional or third party websites are prohibited.

In most cases authors are permitted to post their version of the article (e.g. in Word or Tex form) to their personal website or institutional repository. Authors requiring further information regarding Elsevier's archiving and manuscript policies are encouraged to visit:

http://www.elsevier.com/copyright 
Analysis

\title{
Motivation crowding in environmental protection: Evidence from an artefactual field experiment
}

\author{
Giovanna d'Adda \\ Università L. Bocconi, Via Roentgen 1, 20133 Milan, Italy
}

\section{A R T I C L E I N F O}

\section{Article history:}

Received 6 December 2010

Received in revised form 6 June 2011

Accepted 6 June 2011

Available online 15 July 2011

\section{JEL Classification:}

D03

D62

013

Keywords:

Social norms

Motivation crowding

Artefactual experiment

Latin America

Bolivia

\begin{abstract}
A B S T R A C T
This paper examines how motivation, crowding and social image affect environmental conservation decisions. An artefactual field experiment conducted in Bolivia is used to reproduce the trade-off between individual and social benefits in natural resource use and test the effect of non-monetary and non-regulatory incentives on pro-social behavior for environmental conservation. The results show the presence of a social norm prescribing positive contribution towards environmental protection, and that external incentives have heterogeneous effects on pro-social behavior depending on how they influence reputation and self-image. The experimental results differ from those of analogous experiments conducted in the laboratory, and are instead consistent with those from field experiments on common-pool resource management. This fact suggests caution in generalizing conclusions, reached in the laboratory, to different settings and populations. (c) 2011 Elsevier B.V. All rights reserved.
\end{abstract}

\section{Introduction}

Common-pool resources (CPR) are characterized by non-excludability and rivalry in consumption. The difficulty of excluding individuals from use and the fact that consumption by one individual reduces the amount of resource available to others imply that $\mathrm{CPR}$ users face a typical cooperation dilemma. Each individual depends on the resource for her livelihood and has the incentive to maximize her own benefit by increasing extraction. However, if everyone follows the same rationale, the resource will be depleted and will not generate benefits for anyone in the long term. In an influential article, Hardin (1968) claims that the behavior of rational, self-interested individuals is bound to result in overexploitation of CPR. This conclusion is consistent with game theoretical predictions and is confirmed by numerous examples of overharvesting of renewable natural resources, such as fisheries, forests and groundwater.

Solutions to the cooperation dilemma have focused on the establishment of external regulations for extraction, property rights to the resource or, more recently, payment for environmental services schemes. These interventions assume that individuals are rational and self-interested. However, research on CPR management questions this vision, by offering evidence of effective cooperation to solve commons problems. Field experiments show that collective action is most

E-mail address: giovanna.dadda@phd.unibocconi.it. effective when communities are able to self-organize, design and enforce their own rules (Baland and Platteau, 1996; Ostrom, 1990; Wade, 1986). Other studies report cases in which changes from a system of self-governance to one of external regulation generate a shift from community norms of cooperation to selfish strategies of extraction (Ostrom, 2006; Vatn, 2006).

One explanation for the failure of external interventions on the sustainability of CPR management is that these measures crowd-out intrinsic motivation, leading to a change in behavior among community members. Individuals may engage in conservation of CPR because they think it is important or because they feel a moral duty to do so. If this is the case, the introduction of external regulations or incentives can change people's perception of the behavior. Voluntary goodwill is turned into a market-like interaction, resulting in fewer people willing to sacrifice for the common good. Benabou and Tirole (2006) argue that motivation crowding acts through the effect of external incentives on individual social and selfimage. By lowering the value of pro-social choices as signals of one's own moral qualities, external incentives can crowd-out individuals' intrinsic motivation to behave pro-socially. The empirical relevance of the crowding-out effect is confirmed by a number of studies, starting from Titmuss' (1970) seminal contribution on blood donation. Field experiments show that pro-social behavior decreases after the introduction of monetary rewards (Frey et al., 1996; Frey and Götte, 1999) and that the crowding-out effect is heterogeneous across individuals (Charness and Gneezy, 2009). 
This study uses an artefactual field experiment on CPR conservation to explore two under-researched issues in the literature on crowding-out. The first is the effect of non-monetary and nonregulatory external incentives on motivation crowding in a field setting. The second is the heterogeneity of motivation crowding effects depending on individuals' intrinsic motivation. This topic is best explored using anartefactual field experiment as methodological tool. This type of experiment selects its participant pool from actual users of the natural resource and confronts participants with a natural task, reflecting the trade-off between individual short-term and social long-term benefits that they face in their daily use of the CPR. ${ }^{1}$ Survey data complement the experimental results, which makes it possible to examine the effect of cultural, social and other contextual factors on individual behavior.

The experiment was conducted in two rural villages in the SouthEast of Bolivia, with users of forest and groundwater resources. The experimental choice was that of contributing to the conservation of these CPR. By donating part of their endowment, participants could finance the purchase and planting of trees around the water source and thus increase the future social benefits from CPR. The design introduced external incentives to donate, in the form of priming for socially approved behavior. The empirical analysis investigates whether the effect of priming differs depending on participants' intrinsic motivation, captured by their level of civic engagement and individualism. The data analysis also examines whether motivation crowding acts through the effect of incentives on social or self-image, by exploiting the public nature of choice under one experimental treatment and existing relationships between participants observing each other's choices.

On average, participants contribute a positive amount, around two-fifth of their endowment. This result is consistent with the presence of a social norm of cooperation for the conservation of CPR. All treatments have a positive effect on contributions to the reforestation project by individualistic participants. On the contrary, civically engaged individuals appear less sensitive to the priming embodied in the experimental treatments. When decisions are private, individuals who belong to the same family or community associations give similar amounts. When decisions are public, the amounts donated by members of the same family are more diverse, while those donated by members of the same community associations are still homogeneous. The different effect on observable and unobservable choices of sharing a social link in the public rather than in the private sphere is interpreted as evidence of the role of social image on pro-social behavior.

The next section examines relevant contributions in the literature on crowding-out and CPR management and presents testable predictions. Section 3 describes the setting and design of the study. The experimental results are discussed in Section 4. Section 5 concludes with some policy implications for the design of CPR interventions.

\section{Literature and Behavioral Predictions}

According to Frey and Stutzer (2006), three conditions increase the probability that external incentives lead to crowding-out of prosocial behavior. Crowding-out is more likely to occur if incentives are perceived as restrictive and controlling; if they reduce the degree of individual self-determination; and if the setting in which they are introduced is one where norms of cooperation and reciprocity are in place. In this section, I will present theoretical contributions and empirical evidence in support of these claims, focusing in particular on experimental studies that show these effects at work in the realm of CPR management.

${ }^{1}$ For a discussion of different types of experiments used in CPR research, see Anderies et al. (2011).
A number of theoretical studies model the mechanisms behind motivation-crowding effects. Two main approaches are used. In the first, external incentives affect intrinsic motivation by changing preferences (Frey, 1994). The second approach models external interventions as changing the perceived nature of a task, the task environment or the agent's self-perception, and through these channels influence the motivation to perform the task. Benabou and Tirole (2006) claim that external incentives affect intrinsic motivation to behave altruistically by lowering the signaling value of pro-social choices. Ellingsen and Johannesson (2008) also formalize the damaging effect on morale of pecuniary incentives and control systems.

Frey and Jegen (2002) offer a review of motivation crowding theory, where they discuss two psychological processes behind the effect of external incentives on intrinsic motivation. The first process focuses on self-determination: external interventions perceived to impair self-determination, reduce intrinsic motivation by replacing it with external control. The second channel focuses on self-esteem: an agent's intrinsic motivation is rejected by interventions that do not acknowledge her involvement and competence. Intrinsically motivated individuals are deprived of their chance of showing their involvement in an activity when someone offers a reward or orders them to do it (Frey and Jegen, 2002).

Monetary sanctions and restrictive regulatory systems have been shown to lead to lower levels of pro-social behavior in a wide range of settings. In a field experiment, Gneezy and Rustichini (2000) look at the introduction of fines for parents who arrive late to pick-up their kids from a day-care center. Introducing the fines leads to an increase in late arrivals by parents. Even after the removal of the fine, the initial level of cooperation by parents cannot be reached anymore. In a laboratory experiment, Falk and Kosfeld (2006) show that similar crowding-out effects are produced by the introduction of regulations restricting participants' choice set in a principal-agent relationship.

The existing literature also demonstrates how the crowding-out effect is heterogeneous depending on individual level of intrinsic motivation. Charness and Gneezy (2009) conduct a field experiment in which they introduce monetary incentives to encourage people to exercise. The incentives have a different impact on gym attendance depending on its level before the introduction of the reward: a positive one on non-regular attendees, and a negligible, and negative, one on individuals who previously attended the gym regularly. The crowding-in effect of incentives prevails for individuals with low intrinsic motivation, while this effect is absent, or even reversed, for highly motivated subjects.

In the field of CPR management, a large number of artefactual experiments focus on the effect of the introduction of regulation by an external authority. When sanctions are imposed without negotiation with resource users they cause crowding-out by undermining selfdetermination and shifting responsibility away from users to an outside entity (Cardenas et al., 2000; Ostmann et al., 1997). Experiments show that giving CPR users the possibility to decide over rules increases the efficiency of the management system. Being allowed to vote for sanctions fosters cooperation (Vyrastekova and van Soest, 2003), as does the introduction of enabling rather than controlling interventions (Vollan, 2008). Both in laboratory and field settings, introducing the possibility of face-to-face communication reduce the level of CPR extraction (Cardenas, 2000; Ostrom and Walker, 1991). Finally, settings where both rule formation and sanctioning are decentralized lead to CPR usage close to the social optimum (Ostrom et al., 1992).

In some cases, external incentives can crowd-in pro-social behavior. A large number of conventional experiments, i.e. experiments conducted in the laboratory with student samples, show that priming on the socially approved behavior has a positive effect on altruism. Increasing observability of choices and reducing social distance among participants generate higher average contributions in 
dictator games (Bohnet and Frey, 1999; Hoffman et al., 1996), as does observing others behaving altruistically and focusing one's attention on the existence of a norm (Krupka and Weber, 2009). The introduction of decentralized costly punishment increases investment in the common project in public good games (Fehr and Gaechter, 2000). Crowding-in is more rarely observed in field settings and CPR artefactual experiments. Castillo and Saysel (2005) show that external regulation triggers higher cooperation levels among fishermen on a Caribbean island, while Rodriguez-Sickert et al. (2008) find that increasing sanctions and enforcement probability eventually yields to cooperation levels close to those under self-governing systems.

Artefactual and conventional experiments yield different predictions on the effect of external incentives on intrinsic motivation to behave pro-socially: a negative effect in the former set of studies and a positive one in the latter. This difference may be due to the different types of incentives analyzed by the two streams of literature. Regulatory and monetary incentives are the main focus of field experiments on CPR management, while non-monetary and nonregulatory factors, such as priming, are generally studied in laboratory studies on norms compliance. Regulations and monetary rewards are likely to be perceived as controlling and lead to crowding-out, according to Frey and Stutzer's (2006) theory. More subtle incentives, such as those used in priming, are less likely to trigger such reaction. The positive effect of priming on norm compliance has rarely been tested in the context of CPR management. The present study aims to fill this gap.

The difference between the conclusions reached by conventional and artefactual experiments may also depend on the fact that the two sets of studies use different subject pools. Student samples may differ from community members and CPR users in the crucial dimension of the social norms that they share. Frey and Stutzer (2006) argue that the level of crowding-out depends on existing norms of cooperation and reciprocity. Vollan (2008) shows that the introduction of controlling regulations produces stronger crowding-out of cooperative behavior among groups with high levels of trust. The bulk of evidence on crowding-in comes from subject pools linked by weak norms of cooperation. The present study complements this literature by bringing treatment designs typical of laboratory experiments to a subject pool of actual CPR users. $^{2}$

The empirical and theoretical literatures on crowding-out suggest that intrinsically motivated individuals may be less pro-social when decision environments signal in a strong and salient way the desired behavior. In such cases "the individual will attribute the performing of the [..] task to the external incentives", while in their absence "the individual would have attributed the execution of the task to the intrinsic features of the task" (Fehr and Falk, 2002, 714). Nonmonetary and non-normative incentives, priming individuals to the appropriate behavior, may have motivation crowding effects similar to monetary and regulatory ones. Whether priming leads to heterogeneous motivation crowding, depending on individual intrinsic motivation to behave pro-socially, is the main focus of this study.

Two testable predictions follow from the discussion of the literature conducted here. First, priming on the approved behavior will negatively affect pro-social choices of individuals with high valuation of the $\mathrm{CPR}^{3}$ because the negative effect of priming on selfimage should be stronger for socially engaged individuals. Second, priming on the approved behavior will affect pro-social choices differently depending on whether one's donation is observed and on

\footnotetext{
${ }^{2}$ The decision to conduct the research in a field setting presents both advantages and disadvantages. It maximizes the relevance of the study for the design of CPR management systems and fills a research gap. However, these benefits come at the cost of lower experimental control and higher levels of heterogeneity of the sample. These advantages and disadvantages will be apparent in the discussion of the experimental results.

${ }^{3}$ This equals saying that crowding-in effects are expected to be stronger for less motivated individuals.
}

who observes it. If behaving unselfishly has a positive signaling value on one's moral qualities, then this value will vary depending on the type of relationship between a player and those who observe her choices. These predictions will be tested in the empirical analysis.

\section{Experimental Setting and Design}

\subsection{Setting}

The study took place in Bolivia, on the edge of the Andean rainforest. Two communities were selected in the municipality of Quirusillas, in the south-west of the Department of Santa Cruz. Although only $5 \%$ of the municipal area is suitable for farming activities, due to the presence of steep mountains, people practice agriculture and livestock raising on $65 \%$ of the municipal land. Ninety four percent of households own land, 21 ha on average in size (INE, 2001). Low productivity subsistence agriculture is the dominant production system, monoculture is common and soil conservation practices, such as crop rotation, are rarely adopted. Land clearing occurs mainly due to the widespread practice of slash-and-burn agriculture, since timber extraction for commercial purposes is not frequent. Overall, overexploitation of land is associated with increasing incidence of soil erosion and flooding in the area (Plan de Desarrollo Municipal, 2003).

The study area was identified through collaboration with a local NGO, Fundacion Natura Bolivia (FN). Since 2003 FN has promoted environmental conservation through the establishment of Payment for Environmental Services schemes in Santa Cruz. At the time of the project, FN was about to start work in the study area. Municipal authorities were consulted to identify communities that suffered from deforestation-related environmental problems. The shortlisted communities were visited to assess the presence of communal land in need of reforestation, its size and proximity to the water source. Presence of communal land was necessary to ensure that participants perceived the project as a common good. Proximity to a water source was crucial to guarantee feasibility of the reforestation project. It is important to note that trees planted along stream banks prevent soil erosion and thus improve water quality.

The two villages that took part in the study are located along the same valley, one at the feet of the mountains and the other at higher elevation. The former is larger and closer to the municipal capital, while the latter is smaller and more isolated. The two communities are connected by a dirt road and the distance between them can be covered in half an hour by car. Seventy eight individuals participated to the experiment, which took place over two one-day sessions. One member from each household, preferably the household head or the spouse, was invited to the experiment several days in advance. Attendance was around 80\% downstream and nearly perfect upstream, thanks to the monetary compensation offered for participation, which minimized selection concerns. ${ }^{4}$

Table 1 presents basic characteristics of participants and of the two communities. Participants are similar in terms of age, education and gender, and of their behavior and opinions towards the environment. They rely on the forest for firewood, timber, other forest products and water. The belief that forest cover is linked to quality and quantity of water is shared by more than half of the participants, and about $70 \%$ of them identify deforestation as the main threat to the environment. The two communities differ in terms of infrastructural development and environmental problems. Around half of participants' households in the more remote upstream community rely on local streams for domestic water supply, while virtually everyone downstream has

\footnotetext{
${ }^{4}$ Participants were given a show up fee equal to one day's wage (40 Bolivianos, about 6 USD). Although the experiment and post-game interview took about two hours, participants were required to wait both before and after play, in order to ensure rigorous randomization across treatments and minimize contamination respectively.
} 
Table 1

Characteristics of participants in the two communities taking part in the study: $t$-test for equal group means.

\begin{tabular}{|c|c|c|c|}
\hline & $\begin{array}{l}\text { (1) Mean of [var] among participants } \\
\text { in the downstream community }(n=48)\end{array}$ & $\begin{array}{l}\text { (2) Mean of [var] among participants } \\
\text { in the upstream community }(n=30)\end{array}$ & (3) P-value \\
\hline \multicolumn{4}{|l|}{ Socio-demographic characteristics } \\
\hline Age & $40.2(2.168)$ & $42.7(2.920)$ & $.494^{*}$ \\
\hline Female (\%) & $47.9(.073)$ & $43.3(.088)$ & .210 \\
\hline Years of education & $5.937(.535)$ & $5.517(.531)$ & .602 \\
\hline Has piped water $(\%)$ & $97.9(.021)$ & $53.3(.093)$ & $.000^{* * *}$ \\
\hline Has electricity (\%) & $52.1(.073)$ & $10(.056)$ & $.000^{* * *}$ \\
\hline Owns land (\%) & $79.2(.059)$ & $86.7(.063)$ & .408 \\
\hline Owns livestock (\%) & $66.7(.069)$ & $53.3(.092)$ & .244 \\
\hline \multicolumn{4}{|c|}{ Benefits from the forest (\% who mentions the following) } \\
\hline Water quantity or quality & $54.2(.073)$ & $50(.093)$ & .724 \\
\hline Firewood or timber & $31.2(.067)$ & $36.6(.089)$ & .627 \\
\hline Extracts products from the forest (\%) & $77.1(.061)$ & $72.4(.084)$ & .650 \\
\hline Deforestation is main threat $(\%)$ & $70.8(.066)$ & $76.7(.085)$ & .578 \\
\hline \multicolumn{4}{|c|}{ Main cause for loss of harvest in the past 3 years (\% who mentions the following) } \\
\hline Drought & $60.4(.071)$ & $43.3(.092)$ & .145 \\
\hline Flood & $16.7(.054)$ & $46.7(.093)$ & $.004^{* *}$ \\
\hline \multicolumn{4}{|c|}{ Community problems (\% who mentions the following) } \\
\hline Water & $70.8(.066)$ & $76.7(.078)$ & .578 \\
\hline Erosion & $41.6(.072)$ & $36.6(.089)$ & .666 \\
\hline \multicolumn{4}{|l|}{ Social preferences } \\
\hline Community work & $4.667(1.105)$ & $2.517(.402)$ & .145 \\
\hline Independence (\%) & $37.5(.071)$ & $30(.085)$ & .504 \\
\hline
\end{tabular}

Note: Std. errors in parenthesis.

*** Significant at $1 \%$.

** Significant at $5 \%$.

* Significant at $10 \%$

access to piped water within their homestead. Droughts and floods are the main cause for the loss of harvest in the downstream and upstream community respectively. ${ }^{5}$

Participants could contribute money to plant trees along the community's water source. Native trees, commonly known as ceibo, ${ }^{6}$ were chosen for the reforestation project. Local biologists suggested this type of tree for different reasons. First, its deep roots make it effective for soil conservation. Second, ceibo would favor biodiversity in the area, since an endangered species of parrots likes to feed on its flowers. Third, if planted at the time of the study, ceibo was likely to survive requiring neither irrigation nor work on the part of community members. Finally, it has no commercial value and is planted only for soil and water conservation. A local saying on ceibo claims that it attracts the water.

In order to minimize uncertainty on the actual use of players' contributions, tree seedlings were brought to the experiment sites. Participants were informed that the trees would be planted the following day. Since there was more than one water source in both communities, it was agreed that the allocation of plants between sources would be decided by participants at the time of planting. To reduce the influence of self-interested motives on experimental decisions, the possibility of being remunerated for planting the trees was not mentioned. ${ }^{7}$ Results from the game were presented and discussed in a meeting with community members the day following the experiment. Participants to the meeting decided on the allocation of the trees and were invited to plant them. Their remuneration was agreed with local authorities.

\footnotetext{
${ }^{5}$ The frequency of floods upstream is a consequence of the fact that land is very steep there due to closeness with the mountains.

${ }^{6}$ Erythrina crista-galli.

7 A failure to control for expectations about future labor income adds an unobservable source of heterogeneity that should be orthogonal to treatment and not bias results across experimental groups.
}

This section has shown how the experiment was designed so as to prevent the reforestation project from being a potential source of income for participants. Contributions to the experiment should thus be driven by the desire to contribute to the conservation of a common resource.

\subsection{Design}

Each participant in the experiment decided how much to contribute to a reforestation project from an endowment of 50 Bolivianos. $^{8}$ The possible choices ranged from 0 to 50 in intervals of 5 Bolivianos, the amount needed to purchase and plant 2 trees. Each participant could therefore purchase and plant up to 20 trees. The decision of whether to contribute some unearned money for planting trees on public land differs under important respects from farmers' resource-use decisions. However, it induces a similar trade-off between certain, short term private benefits and uncertain, long term social costs. It is also similar to actual conservation decisions taken by community members, such as supplying labor or materials for the protection of springs. The assumption behind this design choice is that contributions are positively correlated with individual valuation of the reforestation project in particular, and of environmental conservation in general. ${ }^{9}$

The design has a between-subjects, four-by-one structure. Each participant was randomly assigned to one of four treatment groups. Relative to the control treatment (private treatment), the other three conditions introduce different types of non-monetary, non-regulatory priming on the socially approved behavior. The treatments are inspired by designs used in the experimental literature to identify

\footnotetext{
${ }^{8}$ This amount is slightly larger than a day's wage, and corresponds to about 7 USD.

9 Beliefs on the appropriateness of the reforestation intervention, on the survival probability of trees and on the private benefits that could be gained from the project vary across individuals and affect contributions within the experiment, but this should not invalidate the basic assumption. Moreover, beliefs should not vary systematically across treatments thanks to randomization.
} 
Table 2

Randomization table: Kruskal-Wallis $\mathrm{H}$ test of between group differences across participants from both communities assigned to the four treatment groups.

\begin{tabular}{|c|c|c|}
\hline & (1) H-statistics & $\begin{array}{l}\text { (2) Probability that the groups were drawn } \\
\text { from the same chi-square distribution }\end{array}$ \\
\hline \multicolumn{3}{|c|}{ Socio-demographic characteristics } \\
\hline Age & 2.991 & 39.3 \\
\hline Female (\%) & 4.029 & 25.8 \\
\hline Years of education & .569 & 90.3 \\
\hline \multicolumn{3}{|l|}{ Services and land use } \\
\hline Has piped water (\%) & 2.222 & 52.8 \\
\hline Owns land $(\%)$ & 1.463 & 69.1 \\
\hline Owns livestock (\%) & 3.590 & 30.9 \\
\hline \multicolumn{3}{|c|}{ Main cause for loss of harvest in the past 3 years (\% who mentions the following) } \\
\hline Drought & 1.098 & 77.7 \\
\hline Flood & .554 & 90.7 \\
\hline \multicolumn{3}{|l|}{ Social preferences } \\
\hline Community work & .050 & 99.7 \\
\hline Independence (\%) & 1.378 & 71.1 \\
\hline
\end{tabular}

Note: Column 1 shows the H-statistics, which represents the variance of the ranks among groups, with an adjustment for the number of ties, and is approximately chi-square distributed. Column 2 gives the $\mathrm{P}$-value corresponding to a chi-square equal to $\mathrm{H}$, representing the probability of getting a particular value of $\mathrm{H}$ by chance if the null hypothesis, that the groups are drawn from the same distribution, is true. The degrees of freedom of the chi-square distribution are the number of groups minus 1 .

drivers of pro-social behavior. They prime participants on the appropriate conservation choice in different ways - giving information on others' choices (information treatment), making decisions public (public treatment) and introducing the possibility of punishment (punishment treatment) respectively - each leveraging a specific mechanism found to sustain social norms. ${ }^{10}$ Each treatment is described in detail below.

The design allows a comparison of choices under different conditions, which I conduct in two stages. First, by considering each treatment separately, I explore which mechanisms behind norm compliance are relevant in this setting. Second, by pooling all forms of priming together, I analyze the effect of priming on intrinsic motivation. Survey questions on social values, cooperation, trust in local institutions, knowledge and opinions on environmental issues complement the experimental evidence and help identify factors correlated with decisions within the game.

Table 2 tests the presence of statistically significant differences between members of different treatment groups using the KruskalWallis $\mathrm{H}$ test. ${ }^{11}$ Participants in different treatments do not differ significantly along any demographic characteristic, nor along any of the variables that will be used in the empirical analysis.

The sessions proceeded as follows. As participants arrived, they were randomly assigned to one of the four treatment groups, each of which was seated in a separate waiting area. The order of treatments was also randomized. Once the first group finished, the second group was called in, and so on. Each group was taken to a room, where the experimenter read the instructions and explained the experimental decision in detail. Participants then proceeded one by one to a second room, where they made their decision in private. The experimenter was present to make any clarifications, ask comprehension questions and assist illiterate participants with filling in the decision sheet. ${ }^{12}$

\footnotetext{
10 The labels given here to the experimental treatments - private, information, public and punishment - are for exposition purposes only. No mention of such labels was made during the experiment. Appendix 2 contains an English version of the experimental instructions.

${ }^{11}$ The Kruskal-Wallis test is a multiple sample generalization of the two-sample Mann-Whitney rank sum test. Samples from different groups are pooled and ranked in ascending order of magnitude. The ranks of observations from each group are summed. The Kruskal-Wallis test tells the probability that the different groups ranksum distributions come from the same distribution. The small size of the sample makes this non-parametric test preferable to parametric k-sample significance tests.

12 Group members waiting to make their decisions remained in the first room. There they waited in the company of an experiment assistant, who made sure that they did not talk to each other.
}

Participants capable of completing the decision sheet on their own were left alone in the room to write down their contribution. When the experimenter re-entered the room, he asked the participant to guess the most frequent choice by people who had previously faced the same decision. These steps were common to all treatments.

Participants in the private and information treatments the second room at this point left and proceeded directly to be interviewed by an enumerator. Participants in the public and punishment treatments were taken to a third room, where they waited for all members of their groups to make their choices. The specific features of each treatment are as follows.

In the private treatment, the contribution choice was kept secret. Each person assigned to this treatment was told that nobody, apart from the researcher handing out the payments, would know her contribution. This treatment isolates intrinsic valuation of the reforestation project. When the amount given is unobservable, intrinsic valuation should be its main determinant. Experiments in the laboratory show that greater anonymity is associated with lower contributions in dictator games (Eckel and Grossman, 1996). Since the main objective of this study is analyzing the effect of external incentives on conservation choices, relative to a situation where no priming takes place, the contribution in the private treatment is used here as the basic proxy of intrinsic motivation. This treatment serves as a baseline and is the omitted category in all regressions in the data analysis, which allows me to directly observe the effect of the different forms of priming relative to the case where no priming takes place.

In the information treatment, each participant was shown a card and told that it reported the contribution of someone who had played the game before. ${ }^{13}$ This information was given to participants just before they made their choices, while alone with the experimenter. This treatment primes participants on the appropriate behavior in different ways: they learn the appropriate behavior by observing the actions of others; their attention is focused on the existence of a norm; and the observed contribution suggests what behavior is considered as appropriate by other participants. Krupka and Weber (2009) refer to these three channels as the informational, focusing and prescriptive roles of social norms, respectively. In their study, which inspired this treatment, they find that individuals exhibit greater compliance with

\footnotetext{
${ }^{13}$ Results from a pilot test of the game were used to draw the decision shown to participants in this treatment. The same contribution, equal to 35 Bolivianos, was shown to all participants to this treatment.
} 
a norm when they observe others doing so and when their attention is focused on the existence of a norm. ${ }^{14}$

Participants in the public treatment were informed that they would announce their contribution to others in their group. This information was given to them while in the group and again when alone with the experimenter. Group members made their choice in private and then went to a third room. There they were asked to announce their contribution to each other. Participants from other treatment groups were not allowed to listen to the contribution announcements. Experiments in the laboratory where behavior is observable by others have been used to measure the effect of social pressures on conformity with the norm (Andreoni and Bernheim, 2009). Pro-social behavior typically increases when decisions are made public. The difference between private and public outcomes is believed to capture the reputation effect of norm compliance. If natural resource conservation sends positive signals on the type of person one is, then this treatment should prime participants on the appropriate behavior through the reputational effect of contributing to reforestation.

The punishment treatment randomly assigned participants to the role of Player 1 or of Player 2. Player 2s could, at a cost to themselves, sanction choices by Player $1 \mathrm{~s}$ that they believed to be socially inappropriate. Player 2s payoffs within the game were not directly affected by Player $1 \mathrm{~s}$ ' reforestation decisions. However, as Player $1 \mathrm{~s}$ and $2 \mathrm{~s}$ were members of the same community, all of them would be affected by the reforestation project outside the game context. The impact of Player 1's contribution on Player 2's utility depended on the latter's valuation of the reforestation project and preferences for fairness.

Players in both roles made their choices in private. The procedure for Player s mirrored the one for participants in the private treatment. Player $2 s$ were given an endowment of 25 Bolivianos $^{15}$ and were asked if they wanted to reduce their own winnings by 5 Bolivianos in order to reduce Player 1's winnings by 10 Bolivianos, or if instead they wanted to leave things as they were. ${ }^{16}$ Designs allowing for costly punishment have been used in the laboratory to identify the role of social sanctions in norm compliance. These studies show that the possibility of being sanctioned increases pro-social behavior, and that participants are willing to sacrifice some of their own endowment in order to punish others, even if they are not directly affected by their decisions (Fehr and Fischbacher, 2004). The introduction of the threat of sanction is the mechanism through which this treatment primes participants on the appropriate behavior.

The strategy method was used for Player $2 \mathrm{~s}$, so they took the punishment decision for each possible contribution to the reforestation project. Participants knew before playing that they would be randomly paired with another player. They also knew how the combination of the decisions of Players 1 and 2 would determine each person's winnings. The matching procedure was public and transparent, so as to make clear to all that it was anonymous and random: each participant's decision was placed in an envelope, and envelopes were put in two boxes labeled 1 and 2 respectively. After all participants had played, the group was taken to a third room where the experiment assistant randomly paired each envelope from box 1 to one envelope from box 2 .

The decision to use the strategy method was influenced mainly by the desire to make the methodology comparable to that used in laboratory third-party punishment experiments (Fehr and Gaechter, 2000), and by logistical considerations which made the application of

\footnotetext{
14 The information treatment in this study combines the informational, focusing and prescriptive channels and therefore does not allow disentangling the role of each one in affecting experimental outcomes.

${ }^{15}$ Equal to half of Player $1 \mathrm{~s}$ ' endowment and worth about 3.5 USD.

${ }^{16}$ A table with all possible combinations of payoffs was shown to the group: each combination was explained to the participants using the word reduce instead of the word punish.
}

Table 3

Mean of experimental outcomes, by treatment group.

\begin{tabular}{ccc}
\hline & $\begin{array}{l}\text { (1) Contribution } \\
\text { (Bolivianos) }\end{array}$ & $\begin{array}{l}\text { (2) Guess of average contribution } \\
\text { to reforestation among others facing } \\
\text { same decision (Bolivianos) }\end{array}$ \\
\hline Private treatment & 22.5 & 20.71 \\
& $(15.441)$ & $(9.579)$ \\
Information treatment & 15.357 & 23.571 \\
& $(10.278)$ & $(10.082)$ \\
Public treatment & 22.5 & 20.5 \\
Punishment treatment & $(12.407)$ & $(10.748)$ \\
Overall & 16 & 18.167 \\
& $(12.276)$ & $(10.462)$ \\
Number of Obs & 19.365 & 20.192 \\
& $(12.841)$ & $(10.302)$ \\
\hline
\end{tabular}

Note: Standard deviations in parenthesis.

the direct-response method in a field setting extremely challenging (Casari and Cason, 2009). The strategy method, while having the advantage of allowing higher statistical depth in the analysis of punishers' decisions, especially at the nodes that are rarely reached in sequential play, may affect behavior relative to the direct-response method. For instance, it could reduce the influence of emotions on experimental choices. Whether the strategy method leads to different choices than when participants respond to actual choices is still an open question. ${ }^{17}$

The experiment also had a belief elicitation component. After deciding how much to contribute to the reforestation project, participants to all treatments were asked to guess what the majority of players, who faced the same decision that they had just taken, had contributed in previous sessions of the experiment. Correct guesses were rewarded with an additional 10 Bolivianos. Elicited beliefs were specific to the treatment each participant had been randomly assigned. They are therefore expected to respond to the different decision environments embodied in the treatments. The experimental literature uses similar belief elicitation methodologies to identify the social norms at work in specific decision setting. Krupka and Weber (2008) show how elicited beliefs on average behavior respond to changes in the decision environment. They believe this finding to suggest that there are no absolute social norms, but that the socially approved behavior is sensitive to the context. The empirical analysis conducted in the next section tests the effect of experimental treatments both on contributions and stated beliefs.

\section{Experimental Results}

This section is articulated in four parts. In the first, differences in contributions across sites and treatments are discussed. The presence and direction of motivation crowding is tested in the second part, where survey data are used to identify sources of heterogeneous treatment effects. The third part uses dyadic data to test the social image hypothesis, by exploring the relationship between social distance and experimental decisions. Finally, the generalizability of the results beyond the field of environmental conservation is discussed in the fourth part.

\subsection{Experimental Results by Treatment and Community}

Table 3 presents individual contributions to the reforestation project (Column 1) and guesses of the majority's contribution among

\footnotetext{
17 The effect of the choice methodology used on subjects' behavior varies across studies (Brandts and Charness, 2000; Casari and Cason, 2009; Oxoby and McLeish, 2004). Roth (1985) discusses the behavioral reasons behind such differences. For a recent meta-study of the effect of strategy versus direct-response method, see Brandts and Charness, 2009
} 
Pairwise differences in contribution across treatments: $t$-test for equal group means and Mann-Whitney non-parametric test.

\begin{tabular}{|c|c|c|c|c|}
\hline & \multicolumn{2}{|l|}{$T$-test } & \multicolumn{2}{|l|}{ Mann-Whitney test } \\
\hline & $\begin{array}{l}\text { (1) Difference in mean contribution (1st group } \\
\text { mean contrib }-2 \text { nd group mean contrib) }\end{array}$ & (2) P-value & $\begin{array}{l}\text { (3) Prob (contrib. from 1st group } \geq \text { contrib. } \\
\text { from 2nd group) }\end{array}$ & (4) P-value \\
\hline Private versus information & 7.143 & $.161^{*}$ & .622 & .263 \\
\hline Private versus public & 0 & 1.000 & .48 & .846 \\
\hline Private versus punishment & 6.5 & $.218^{* *}$ & .61 & .314 \\
\hline Information versus public & -7.143 & $.086^{* * *}$ & .32 & .076 \\
\hline Information versus punishment & -.643 & .880 & .49 & .891 \\
\hline Public versus punishment & 6.5 & .133 & .69 & .058 \\
\hline
\end{tabular}

Note: Column 3 reports the probability of a randomly drawn value from the first group to be greater than a randomly drawn value from the second group.

* Significant at $10 \%$

** Significant at $5 \%$.

*** Significant at $1 \%$.

people facing the same decision (Column 2) on average by treatment. Mean overall contribution is about 19.4 Bolivianos. Average contribution is lowest in the Information treatment and highest in the private and public treatments. Guesses of the most frequent contribution are also sensitive to group assignment. In particular, participants in the Information treatment display the highest guesses. This is likely to be a consequence of the high contribution example shown to them before their choice.

In order to test whether differences in outcomes across treatments are significant, Table 4 compares average contributions across pairs of treatments, using a parametric and a non-parametric test. The $t$-test of pairwise group differences (Columns 1 and 2) is almost never significant. This is to be expected, given the small group sizes. Column 3 and 4 show results from the Mann-Whitney test, more appropriate with small samples. The probability of a randomly drawn contribution from the first group being higher than a randomly drawn contribution from the second group is reported in Column 3. Column 4 shows the p-value with which the null hypothesis of equal distributions is rejected. Only the difference between the Information and the Public treatment is significant at the $10 \%$ level.

On average, the effect on giving of the information and punishment treatments relative to the private one is negative. This result, though not statistically significant, hints to the negligible role played by information and social sanctions in the decision of contributing to reforestation. The reputational and sanctioning channels have been found to sustain norm compliance in other contexts, but do not appear to be at work in the study setting. This fact may suggest the absence of an established norm of behavior for environmental conservation. This conclusion is supported by the results on giving under the public treatment. When public, donations are on average equal to those in the private treatment. More interestingly, average giving in the public treatment is the same across communities, a possible result of the presence of a norm for contributing to village projects in general, rather than to environmental conservation in particular.

Experimental outcomes clearly differ across communities. Figs. 1 and2 show individual and average contributions by treatment in the two study communities. Downstream, overall average contribution is equal to 14 Bolivianos. Contributions in the private, information and punishment treatments are not statistically different from each other. Participants in the public treatment are the highest contributors in the community: the $t$-test of the difference in average contribution between the public and the remaining three treatments downstream is significant at the $5 \%$ level. For the upstream community the picture is different: contributions are higher than downstream in all treatments but the public one, and differences across treatments are never significant. Overall average contribution upstream is of 24.8 Bolivianos, nearly half of the total endowment. Although a formal test is not possible because only two villages took part in the study, this picture is consistent with the presence of a negative correlation between existing norms of cooperation and motivation crowding: while priming has no effect on donation where initial cooperation is high, it significantly increases contributions, at least in one of form, where cooperation is low.

Next, I use regression analysis and consider four experimental outcomes: contribution amounts, guesses on the majority's contribution, the probability of giving above the average contribution in the community and the probability of giving above one's guess. The first two dependent variables are the two decisions taken by participants in the experiment. The third dependent variable gives a measure of individual cooperation relative to the community average, while the fourth captures the probability that one contributes above what she believes to be the socially approved level.

Regressions in Table 5 include interactions between treatment dummies and community fixed effects:

$y_{i}=\beta_{1}+\beta_{2}$ Treatment $_{i}+\beta_{3}$ Comm $_{i}+\beta_{4}$ Treatment $_{i}{ }^{*}$ Comm $_{i}+\varepsilon_{i}(1)$

where $y_{i}$ denotes each of the four experimental outcomes. The private group is used as the control group relative to which the effect of priming is measured. This choice is maintained throughout the empirical session.

Treatment dummies do not appear to be significant. Insignificant treatment effects are likely to be an unavoidable consequence of the small sample problem that affects this study. The results confirm the differences in treatment effects across communities suggested by Fig. 1. A pattern similar to that outlined for contribution amounts can be detected for other experimental outcomes. Beliefs on average contributions are higher upstream than downstream by 4.6 Bolivianos. ${ }^{18}$ Even so, members of the upstream community contribute more than their believed average contribution $72 \%$ of the time. The corresponding figure is 55\% downstream. Participants upstream contribute more, have higher beliefs on the appropriate contribution level and are more likely to give above such level.

The different behavior of participants living upstream and downstream does not appear to be motivated by different sociodemographic characteristics across locations. Table 6 presents results from regressions of experimental outcomes on age, education and gender, ${ }^{19}$ controlling for community:

$y_{i}=\beta_{1}+\beta_{2}$ Age $_{i}+\beta_{3}$ Education $_{i}+\beta_{4}$ Female $_{i}+\beta_{5}$ Comm $_{i}+\varepsilon_{i}$

Regression coefficients for each socio-demographic variable appear to be rarely significant. Education is positively correlated with outcomes, while the opposite holds for age. They appear to be

\footnotetext{
${ }^{18} 23$ Bolivianos on average upstream against 18.4 Bolivianos downstream: the difference is significant at the $10 \%$ level.

19 The dependent variables are absolute amount contributed (Column 1), dummy equal to 1 if contribution is above the community average (Column 2), beliefs on
} average contribution (Column 3)and contribution above belief (Column 4). 

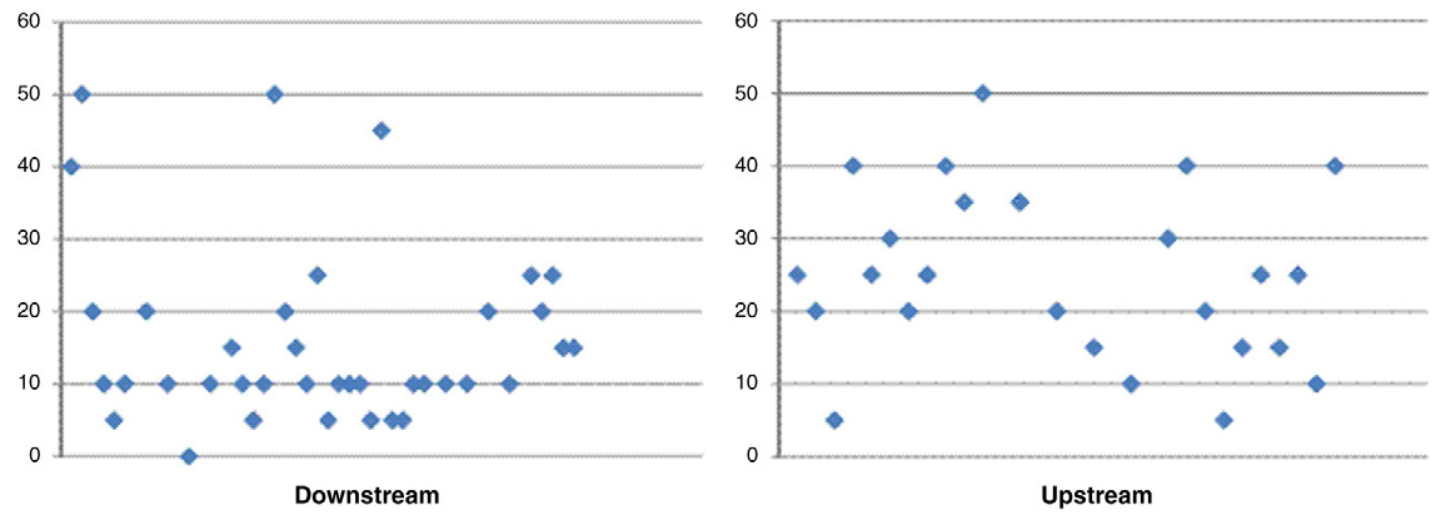

Fig. 1. Individual contributions by community.

significant only for contribution levels. The female indicator variable is negatively correlated with all outcomes but one. The upstream community dummy remains positive and significant even after controlling for individual characteristics.

A second potential explanation for the differences in experimental outcomes across villages concerns the expected returns from the reforestation project. The intervention could have been perceived as more beneficial and useful in the upstream community. ${ }^{20}$ Indeed, survey data confirm this claim. Upstream, $60 \%$ of participants believed that the project would be good for the environment and the community. The corresponding figure is $37.5 \%$ downstream. Since participants were asked for an opinion on the reforestation project after choosing their contribution, these data can at most be suggestive. While one can argue that individuals downstream did not contribute because they thought that the project was not useful, the opposite claim is equally plausible, i.e. that individuals downstream said that the project was not useful because they had not contributed much to it. $^{21}$

A third possible explanation of community level differences in outcomes focuses on the relative population sizes in the two villages. Population downstream is about twice as large as upstream. Ceteris paribus, smaller groups are found to be more effective at ensuring participation in common good provision (Ostrom, 1990), as freeriding incentives increase with group size.

Although the data available do not allow distinguishing between these alternative explanations, it seemed nonetheless important to me to highlight the presence of heterogeneity across villages and discuss its potential causes. While I am not able to explain community level differences, I can explore sources of heterogeneity in giving and in treatment effects at the individual level. This will be the topic of the next subsection.

\subsection{Heterogeneous Treatment Effects}

This subsection looks at sources of heterogeneous effects of treatments. The goal is to test the first behavioral prediction made in Section 2, i.e. that priming on the approved behavior negatively affects pro-social choices if one has a high valuation of the common good. In order to do this, I use a variable equal to 1 if a participant was assigned to the Information, Public and Punishment treatments, and 0 otherwise. This dummy variable identifies situations where some

\footnotetext{
${ }^{20}$ This would be the case if planting trees near the community mitigated negative environmental externalities more in one place than in the other. If much of the contamination of the water occurred before the stream reached the downstream community, for instance, reforestation of a piece of land within the community's boundaries would only result in minor improvements in water quality.

${ }^{21}$ More formally, psychologists say that individuals tend to justify their own choices ex-post, both to themselves and to others, in ways that preserve their self-image (Fehr and Falk, 2002).
}

form of priming on the socially approved behavior takes place, as opposed to the Private treatment, where no priming occurs. The priming dummy is interacted with proxies for intrinsic motivation in order to test the motivation-crowding hypothesis. Two variables are considered: civic engagement, captured by the number of days of community work performed over the previous year; and individualism, revealed by the belief that independence is one of the most important qualities to teach a child. These two variables reflect two correlated, but not overlapping, dimensions of social preferences. ${ }^{22}$

Community work days are a common practice in the region under study. Village members regularly join forces to work on common projects, such as cleaning the square or filling holes in the road. Participation to community work days is not compulsory, but noncompliance is subject to social disapproval. ${ }^{23}$ Survey data show that participation in community work is positively correlated with the number of organizations active in the community known, and with the probability of having helped others in the previous month. ${ }^{24} \mathrm{I}$ therefore use participation in community work as a proxy for civic engagement and intrinsic valuation of the common good.

On the contrary, participants who think that independence is one of the main qualities to teach a child are less likely to be members of community organizations and to take part in community meetings. ${ }^{25}$ The use of this variable as a proxy of individualism is justified by research in the field of social psychology. Hofstede (2001) defines individualism in terms of independent self-construct, which denotes a state where an individual views himself as 'an independent, autonomous person' (Markus and Kitayama, 1991). In a study specifically aimed at identifying indicators of individualism, Gustavsson (2008) finds this particular variable, taken from the World Values Survey, to be a significant proxy.

First of all, I look at how the two intrinsic motivation proxies are correlated with experimental outcomes. Table 7 reports regressions of the four experimental outcomes on community work days and the independence dummy, controlling for community fixed effects. The following regressions are estimated:

$y_{i}=\beta_{1}+\beta_{2}$ Commwork $_{i}+\beta_{3}$ Individ $_{i}+\beta_{4}$ Comm $_{i}+\varepsilon_{i}$

22 The pairwise correlation coefficient is $-18 \%$ and not statistically significant

${ }^{23}$ A small survey implemented in a neighboring municipality by the local partner, FN, supports this claim.

24 Individuals in the top 2 deciles in terms of participation to community work mention on average $32 \%$ more institutions who have been active in the village. They are also $25 \%$ more likely to have lent money or things to neighbors or to have helped strangers over the previous month. One-sided t-tests are significant at the $1 \%$ level.

${ }^{25}$ They are $15 \%$ less likely to be members of the Organizacion Territorial de Base (OTB), the main institution at the village level; and 17\% less likely to attend community meetings. One-sided t-tests are significant at the $10 \%$ level. 

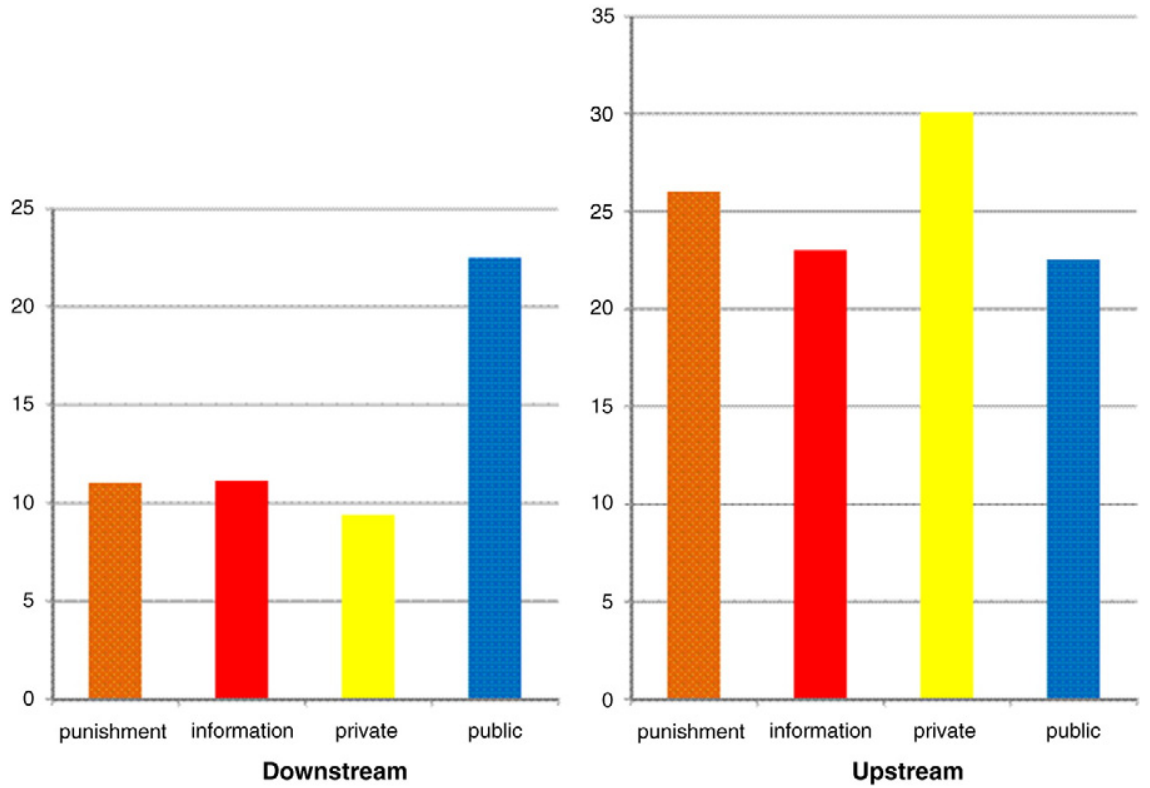

Fig. 2. Average contributions by treatment and community.

Civic engagement is positively and significantly correlated with all experimental outcomes. Individuals who are more engaged in community work give more, are more likely to give above the average in their village, have higher beliefs on others' contributions and are more likely to give above what they believe to be the norm. The opposite holds for individualism, which is negatively correlated with experimental outcomes, significantly only for the probability of contributing above the community average.

Next I consider how civic engagement and individualism, in turn, interact with the priming embodied in experimental treatments. Table 8 shows results from regressions of experimental outcomes on the priming dummy, community work days and the interaction between them:

$y_{i}=\beta_{1}+\beta_{2}$ Priming $_{i}+\beta_{3}$ Commwork $_{i}+\beta_{4}$ Priming $_{i}$

$*$ Commwork $_{i}+\beta_{5}$ Comm $_{i}+\varepsilon_{i}$
The positive correlation between community work and all experimental outcomes is confirmed. The coefficients on the interaction term are positive in all but one case. The net effect of priming, computed by summing the coefficients on the priming dummy and the interaction term, is negative with one exception, the probability of contributing above the norm. Priming negatively affects behavior of participants with high valuation of the good of the community. While not statistically significant, this result is consistent with the prediction of negative motivation crowding of treatments for individuals intrinsically motivated to behave pro-socially.

Table 9 shows results from a similar exercise, only community work is replaced by the independence dummy:

$$
\begin{aligned}
& y_{i}=\beta_{1}+\beta_{2} \text { Priming }_{i}+\beta_{3} \text { Individ }_{i}+\beta_{4} \text { Priming }_{i} \\
& \quad * \text { Individ }_{i}+\beta_{5} \text { Comm }_{i}+\varepsilon_{i}
\end{aligned}
$$

Individualism is negatively correlated with experimental outcomes. Coefficients on interaction terms are positive, large in size and

Table 5

\begin{tabular}{|c|c|c|c|c|}
\hline & (1) Contribution (Bolivianos) & $\begin{array}{l}\text { (2) Prob (Contribution } \geq \text { average } \\
\text { village contribution) }\end{array}$ & $\begin{array}{l}\text { (3) Guess of average contribution among } \\
\text { others facing same decision (Bolivianos) }\end{array}$ & (4) Prob (Contribution $\geq$ guess) \\
\hline Information treatment & $\begin{array}{r}-7.222 \\
(6.166)\end{array}$ & $\begin{array}{r}-0.275 \\
(0.210)\end{array}$ & $\begin{array}{c}2.222 \\
(4.867)\end{array}$ & $\begin{array}{r}-0.214 \\
(0.230)\end{array}$ \\
\hline Public treatment & $\begin{array}{c}4.167 \\
(7.279)\end{array}$ & $\begin{array}{c}0.265 \\
(0.226)\end{array}$ & $\begin{array}{l}1.556 \\
(4.853)\end{array}$ & $\begin{array}{c}0.187 \\
(0.155)\end{array}$ \\
\hline Punishment treatment & $\begin{array}{r}-7.333 \\
(6.104)\end{array}$ & $\begin{array}{r}-0.152 \\
(0.221)\end{array}$ & $\begin{array}{r}-4.194 \\
(4.469)\end{array}$ & $\begin{array}{c}0.245 \\
(0.133)^{*}\end{array}$ \\
\hline Information upstream & $\begin{array}{c}0.222 \\
(8.851)\end{array}$ & $\begin{array}{c}0.079 \\
(0.442)\end{array}$ & $\begin{array}{c}1.778 \\
(7.288)\end{array}$ & $\begin{array}{l}-0.877 \\
(0.045)^{\text {*** }}\end{array}$ \\
\hline Public upstream & $\begin{array}{r}-11.667 \\
(8.882)\end{array}$ & $\begin{array}{l}-0.431 \\
(0.168)^{* *}\end{array}$ & $\begin{array}{r}-4.556 \\
(6.536)\end{array}$ & $\begin{array}{l}-0.950 \\
(0.027)^{* * *}\end{array}$ \\
\hline Punishment upstream & $\begin{array}{c}3.333 \\
(9.886)\end{array}$ & $\begin{array}{r}-0.231 \\
(0.299)\end{array}$ & $\begin{array}{c}5.194 \\
(5.687)\end{array}$ & $\begin{array}{c}-0.894 \\
(0.034)^{* * *}\end{array}$ \\
\hline Upstream & $\begin{array}{l}11.667 \\
(6.738)^{*}\end{array}$ & $\begin{array}{c}0.472 \\
(0.257)^{*}\end{array}$ & $\begin{array}{c}3.556 \\
(4.280)\end{array}$ & $\begin{array}{l}0.962 \\
(0.025)^{* * *}\end{array}$ \\
\hline (Pseudo) R-squared & 0.23 & 0.14 & 0.11 & 0.19 \\
\hline Number of Obs & 63 & 63 & 78 & 63 \\
\hline
\end{tabular}

Regressions of experimental outcomes on treatment dummies, community and interaction of treatment dummies and community.

Note: Private is the omitted category among treatment groups. Upstream dummy equal to 1 for the upstream community and to 0 for the downstream community. Marginal Effect reported for discrete change of dummy variable from 0 to 1 . Robust standard errors.

* Significant at $10 \%$

** Significant at $5 \%$.

*** Significant at $1 \%$ 
Table 6

Regressions of experimental outcomes on demographic characteristics and community dummy.

\begin{tabular}{|c|c|c|c|c|}
\hline & (1) Contribution (Bolivianos) & $\begin{array}{l}\text { ( } 2 \text { ) Prob (Contribution } \geq \text { average } \\
\text { village contribution) }\end{array}$ & $\begin{array}{l}\text { (3) Guess of average contribution among } \\
\text { others facing same decision (Bolivianos) }\end{array}$ & (4) Prob (Contribution $\geq$ guess) \\
\hline Female & $\begin{array}{c}-1.094 \\
(2.882)\end{array}$ & $\begin{array}{c}-0.005 \\
(0.131)\end{array}$ & $\begin{array}{c}1.093^{*} \\
(2.415)\end{array}$ & $\begin{array}{c}-0.108 \\
(0.129)\end{array}$ \\
\hline Age & $\begin{array}{l}-0.159 \\
(0.077)^{* *}\end{array}$ & $\begin{array}{c}-0.007 \\
(0.005)\end{array}$ & $\begin{array}{c}-0.046 \\
(0.057)\end{array}$ & $\begin{array}{c}-0.006 \\
(0.004)\end{array}$ \\
\hline Years of education & $\begin{array}{c}0.132 \\
(0.042)^{* * *}\end{array}$ & $\begin{array}{c}0.013 \\
(0.015)\end{array}$ & $\begin{array}{l}0.126 \\
(0.033)^{* * *}\end{array}$ & $\begin{array}{c}-0.002 \\
(0.003)\end{array}$ \\
\hline Upstream & $\begin{array}{l}9.912 \\
(3.183)^{* * *}\end{array}$ & $\begin{array}{l}0.308 \\
(0.133)^{* *}\end{array}$ & $\begin{array}{l}5.327 \\
(2.402)^{* *}\end{array}$ & $\begin{array}{c}0.165 \\
(0.128)\end{array}$ \\
\hline (Pseudo) R-squared & 0.19 & 0.13 & 0.08 & 0.05 \\
\hline Number of Obs & 63 & 63 & 78 & 63 \\
\hline
\end{tabular}

Note: Community dummy equal to 1 for the upstream community and to 0 for the downstream community. Marginal Effects reported for discrete change of dummy variable from 0 to 1 . Robust standard errors.

$*$ Significant at $10 \%$.
$* *$ Significant at $5 \%$.

$* * *$ Significant at $1 \%$

significant in 3 out of 4 cases. In particular, there is a positive and significant correlation between contributions and priming for individualistic participants. The net effect of priming is also positive for this type of individuals across outcomes, with the exception of the probability of contributing above the norm. Comparing Tables 8 and 9 suggests that priming indeed has a different effect depending on individuals' intrinsic valuation of the common good: while it does not seem to affect highly motivated individuals, it crowds-in pro-social behavior of individualistic ones. This finding mirrors Gneezy and Rustichini's (2000) results on the effect of incentives to exercise.

The most direct evidence of heterogeneous motivation-crowding effects of priming is shown in Table 10. There, contribution amount is regressed on the priming dummy, the civic engagement and independence proxies and the interaction between the priming dummy with the latter two:

$$
\begin{aligned}
\text { Contribution }_{\mathrm{i}}= & \beta_{1}+\beta_{2} \text { Priming }_{\mathrm{i}}+\beta_{3} \text { Commwork }_{\mathrm{i}}+\beta_{4} \text { Individ }_{\mathrm{i}} \\
& +\beta_{5} \text { Priming }_{\mathrm{i}} * \text { Commwork }_{\mathrm{i}}+\beta_{6} \text { Priming }_{i} * \operatorname{Individ}_{i}(6) \\
& +\beta_{7} \text { Comm }_{i}+\varepsilon_{i}
\end{aligned}
$$

This regression uses a different proxy of civic engagement: a variable equal to 1 if individual participation in community work is in the top 2 deciles. This change should make coefficients more comparable across regressors and allow a cleaner identification of intrinsically motivated individuals.

The coefficients on the main effect of community work and independence confirm the results presented above: more socially engaged individuals contribute more, while the opposite holds for more individualistic participants. Experimental treatments have a negative impact on socially engaged individuals' contributions ${ }^{26}$ and a positive impact on individualistic participants' contributions. Focusing attention on the socially approved behavior has opposite effects depending on an individual's pro-social preferences. These results echo findings from the literature on the impact of monetary and regulatory incentives and support the claim that non-monetary and non-regulatory incentives generate similar heterogeneous motivation crowding effects. The next subsection attempts to test one mechanism through which this effect may act.

\subsection{Social Image and Experimental Outcomes}

In this subsection I test the claim that external incentives crowdout intrinsic motivation to behave pro-socially through their effect on social image. An implication of such claim is that one's pro-social

\footnotetext{
26 The coefficient on the interaction term is not significant.
}

behavior should respond to its observability and to the social distance of those observing one's choices. By rectangularizing the individual level dataset, I can look at the relationship between experimental choices of pairs of players, the type of relationship between them and their relative treatment assignment. This analysis uses dyadic regressions (Fafchamps and Gubert, 2007) and considers two dependent variables: the absolute value of the difference between player $i$ and $j$ 's contributions to the reforestation project; and the average between player i and j's contributions. The former captures similarity of two participants' choices. The latter summarizes the pair's level of pro-social behavior.

The influence of social distance on these outcomes is tested using two proxies of social links between participants. The first is a dummy equal to 1 if $i$ and $j$ are relatives, i.e. they share the same surname. The second is the number of community associations which $i$ and $j$ are both members of. These variables are imperfect proxies of two different types of social links. The former is correlated to closeness between two individuals in the realm of their private life. The latter approximates the intensity of interaction between two individuals in the public sphere. The assumption made here is that family relationships are less salient to the experimental decision than relationships in the public sphere. If so, the negative impact on social image of a selfish choice will be lower if observed by relatives than by comembers in community organizations. To test this claim, the two social link proxies are interacted with a dummy variable equal to 1 if players $\mathrm{i}$ and $\mathrm{j}$ are in the same public treatment group:

$$
\begin{aligned}
& y_{i j}= \beta_{1}+\beta_{2} \text { Samepub }_{i j}+\beta_{3} \text { Rel }_{i j}+\beta_{4} \text { Samepub }_{i j} \\
& * \text { Rel }_{i j}+\beta_{5} \text { Comm }_{i}+\varepsilon_{i} \\
& y_{i j}= \beta_{1}+\beta_{2} \text { Samepub }_{i j}+\beta_{3} \text { Sameassoc }_{i j}+\beta_{4} \text { Samepub }_{i j} \\
& * \text { Sameassoc }_{i j}+\beta_{5} \text { Comm }_{i}+\varepsilon_{i}
\end{aligned}
$$

Table 11 presents dyadic regression results. ${ }^{27}$ The dependent variable in Columns 1 and 2 is the absolute value of the difference between $i$ and j's contributions. The dependent variable in Column 3 and 4 is the average of $i$ and $j$ 's contributions. Columns 1 and 3 regress pairs' outcomes on the dummy for $\mathrm{i}$ and $\mathrm{j}$ being relatives, the dummy for $\mathrm{i}$ and $\mathrm{j}$ being in the same public treatment group, and their interaction. Regressions in Columns 2 and 4 replace the relative dummy with the association co-membership variable.

\footnotetext{
27 To correct for correlation between observations, we use the standard error formula proposed by Fafchamps and Gubert (2007) for dyadic regressions. Individual characteristics feature in dyadic regressions in two forms: the absolute value of the difference between $i$ and $j$ 's characteristic; and the sum of $i$ and $j$ 's characteristics (Fafchamps and Gubert, 2007).
} 
Table 7

Regressions of experimental outcomes on days of community work and individualism proxy.

\begin{tabular}{|c|c|c|c|c|}
\hline & (1) Contribution (Bolivianos) & $\begin{array}{l}\text { (2) Prob (Contribution } \geq \text { average } \\
\text { village contribution) }\end{array}$ & $\begin{array}{l}\text { (3) Guess of average contribution among } \\
\text { others facing same decision (Bolivianos) }\end{array}$ & (4) Prob (Contribution $\geq$ guess) \\
\hline Community work & $\begin{array}{l}0.743 \\
(0.146)^{* * *}\end{array}$ & $\begin{array}{c}0.036 \\
(0.019)^{*}\end{array}$ & $\begin{array}{l}0.198 \\
(0.091)^{* *}\end{array}$ & $\begin{array}{l}0.033 \\
(0.016)^{* *}\end{array}$ \\
\hline Independence & $\begin{array}{c}-4.140 \\
(3.170)\end{array}$ & $\begin{array}{c}-0.247 \\
(0.131)^{*}\end{array}$ & $\begin{array}{r}-2.422 \\
(2.509)\end{array}$ & $\begin{array}{c}-0.154 \\
(0.133)\end{array}$ \\
\hline Upstream & $\begin{array}{l}9.809 \\
(2.997)^{* * *}\end{array}$ & $\begin{array}{l}0.286 \\
(0.133)^{* *}\end{array}$ & $\begin{array}{c}4.246 \\
(2.398)^{*}\end{array}$ & $\begin{array}{l}0.184 \\
(0.124)\end{array}$ \\
\hline (Pseudo) R-squared & 0.29 & 0.13 & 0.06 & 0.08 \\
\hline Number of Obs & 62 & 62 & 77 & 62 \\
\hline
\end{tabular}

Note: Community work denotes the number of days of community work that the respondent did over the previous 12 months. Independence is a dummy equal to 1 if the respondent mentioned independence among the 3 most important qualities to teach a child. Community dummy equal to 1 for the upstream community and to 0 for the downstream community. Marginal Effects reported for discrete change of dummy variable from 0 to 1 . Robust standard errors.

* Significant at $10 \%$.

** Significant at $5 \%$.

*** Significant at $1 \%$.

Columns 1 and 2 show that individuals who are related or interact with each other more often in community organizations choose closer contribution levels. The interaction terms have different signs in the two regressions. Being observed by a relative rather than by a comember of community associations appears to have opposite effects on the degree of similarity between one's choice and that of the observer. Individuals who interact with each other more frequently in their public life tend to choose closer contribution levels when assigned to the same public treatment group (although this correlation is not significant). On the contrary, in the same situation relatives display significantly larger differences in contributions. Columns 3 and 4 show the effect of social links and publicity of decision on a pair's average contribution. Relatives appear to give less on average when they are in the same public treatment group than when they are in other treatment groups.

These results may be explained by endogenous sorting of individuals with similar traits into the same organization or family through marriage. ${ }^{28}$ Indeed, Table 11 shows that, when individuals are relatives or belong to the same associations, their contribution levels are closer. This is true across treatments. Endogenous sorting does not explain, however, the difference of the sign for the interaction terms across regressions. When decisions are public, contributions of pairs of relatives are less homogeneous. The opposite holds when the pair is formed by individuals who are members of the same associations. ${ }^{29}$

This difference can be interpreted in terms of the social image costs of different decisions. There is a cost in contributing an amount different from what one expects others to give. The different signs of interaction terms coefficients hint to the fact that this social cost is lower between individuals who interact in the private than in the public sphere. Overall, dyadic regression results are consistent with contribution decisions being affected by their costs in terms of social image. I now turn to the question of generalizability of these results beyond the scope of the experiment presented here.

\subsection{Environmental-Specific Versus General Pro-Social Preferences}

Earlier in this section I observed that experimental giving is positive and fairly constant across treatments. This indicates the presence of social preferences prescribing positive contributions. Such preferences could be specific to environmental conservation, or they

\footnotetext{
${ }^{28}$ Similar preferences within the family could be observed even in the absence of endogenous sorting. For instance, they could be due to genetic factors.

${ }^{29}$ Table A1 shows that these results are robust to the inclusion of participants' age, gender and education level. Obviously, this is only marginally reassuring. If people sort on their propensity to be communal, and this trait is imperfectly proxied by age, gender and education, these results do not rule out endogeneity of association membership.
}

could instead be pro-social preferences towards helping the community, with natural resources simply acting as a conduit. This subsection presents arguments in support of the latter interpretation.

Environmental degradation is a community problem: $73 \%$ of participants rate water-related problems as one of the main issues in their community. The reforestation interventions could have been perceived by participants as a generic project addressing community problems. Unfortunately the experimental design, by focusing on a unique type of intervention, does not allow comparing contribution patterns across different community projects. However, the presence of general pro-social preferences towards helping the community is suggested by participants' behavior in the Public treatment. I observed earlier how the only group experiencing significant treatment effects is the Public one in the downstream community. The Public treatment is also the only one resulting in the same average contribution across communities. Such uniformity might derive from the presence of a standard contribution rule for public projects in both communities. It is unlikely that previous reforestation projects contributed to the formation of such rule. No reforestation activities of the kind presented here had ever taken place in the area. ${ }^{30}$ On the contrary, members of both communities meet regularly to decide contributions to common projects. The practice of community work, as seen earlier in the section, is also widespread.

Another argument in favor of the generalizability of the results focuses on the lack of correlation between experimental outcomes and proxies of environmental valuation. The survey administered to participants included questions on importance given to the environment in general and forests in particular; perception of environmental threats; reforestation conducted on own land; and loss of income due to environmental shocks. Table 12 shows how none of these variables is significantly correlated with experimental outcomes. Proxies of more general social preferences, such as civic engagement and individualism, show more significant correlation patterns with behavior in the game.

Finally, the results on experimental punishment appear to be due to general preferences for fairness rather than to specific preferences for reforestation. Player 2s sanctioned Player 1s 70\% of the times for contributing less than half of the endowment, but only $21 \%$ of the times otherwise (Fig. 3 ). This result can be driven by a desire to punish norm violators, or by spiteful preferences, i.e. by "the desire to reduce another's material payoff for the mere purpose of increasing one's relative payoff" (Fehr et al., 2008, 494). Fig. 4 is consistent with the presence of inequality aversion: sanctions start decreasing for contributions above the amount considered the norm for reforestation contributions, which is 20 Bolivianos, but the largest drop in

\footnotetext{
${ }^{30}$ The only reforestation project, which was mentioned to us, was conducted by the Municipal government about 10 years ago. It consisted in planting pine trees along the slope of the mountain near the upstream village for commercial purposes.
} 
Table 8

Regressions of experimental outcomes on the priming dummy, days of community work and interaction between the priming dummy and days of community work.

\begin{tabular}{|c|c|c|c|c|}
\hline & (1) Contribution (Bolivianos) & $\begin{array}{l}\text { (2) Prob (Contribution } \geq \text { average } \\
\text { village contribution) }\end{array}$ & $\begin{array}{l}\text { (3) Guess of average contribution among } \\
\text { others facing same decision (Bolivianos) }\end{array}$ & (4) Prob (Contribution $\geq$ guess) \\
\hline Priming & $\begin{array}{r}-5.134 \\
(4.339)\end{array}$ & $\begin{array}{r}-0.260 \\
(0.176)\end{array}$ & $\begin{array}{r}-1.090 \\
(2.994)\end{array}$ & $\begin{array}{c}0.040 \\
(0.187)\end{array}$ \\
\hline Community work & $\begin{array}{l}0.591 \\
(0.163)^{* * *}\end{array}$ & $\begin{array}{c}0.011 \\
(0.008)\end{array}$ & $\begin{array}{c}0.160 \\
(0.116)\end{array}$ & $\begin{array}{c}0.047 \\
(0.032)\end{array}$ \\
\hline Priming community work & $\begin{array}{c}0.697 \\
(0.616)\end{array}$ & $\begin{array}{c}0.045 \\
(0.022)^{* *}\end{array}$ & $\begin{array}{l}0.178 \\
(0.324)\end{array}$ & $\begin{array}{r}-0.021 \\
(0.037)\end{array}$ \\
\hline Upstream & $\begin{array}{l}10.263 \\
(2.925)^{* * *}\end{array}$ & $\begin{array}{l}0.294 \\
(0.132)^{* *}\end{array}$ & $\begin{array}{c}4.483 \\
(2.398)^{*}\end{array}$ & $\begin{array}{c}0.185 \\
(0.121)\end{array}$ \\
\hline $\begin{array}{l}\text { Number of Obs } \\
\text { (Pseudo) R-squared }\end{array}$ & $\begin{array}{l}62 \\
0.287\end{array}$ & $\begin{array}{l}62 \\
0.122\end{array}$ & $\begin{array}{l}77 \\
0.055\end{array}$ & $\begin{array}{l}62 \\
0.065\end{array}$ \\
\hline
\end{tabular}

Note: Priming is a dummy equal to 1 if a participant is in the Information, Public and Punishment treatment, 0 if she is in the Private treatment. Community work denotes the numbe of days of community work that the respondent did over the previous 12 months. Community dummy equal to 1 for the upstream community and to 0 for the downstream community. Marginal Effects reported for discrete change of dummy variable from 0 to 1 . Robust standard errors.

* Significant at $10 \%$.

** Significant at $5 \%$

*** Significant at $1 \%$.

Table 9

Regression of the priming dummy, individualism proxy and interaction between treatment dummies and individualism proxy.

\begin{tabular}{|c|c|c|c|c|}
\hline & (1) Contribution (Bolivianos) & $\begin{array}{l}\text { (2) Prob (Contribution } \geq \text { average } \\
\text { village contribution) }\end{array}$ & $\begin{array}{l}\text { (3) Guess of average contribution among } \\
\text { others facing same decision (Bolivianos) }\end{array}$ & (4) Prob (Contribution $\geq$ guess) \\
\hline Priming & $\begin{array}{c}-5.279 \\
(4.552)\end{array}$ & $\begin{array}{c}-0.123 \\
(0.170)\end{array}$ & $\begin{array}{c}-2.122 \\
(2.964)\end{array}$ & $\begin{array}{c}0.004 \\
(0.166)\end{array}$ \\
\hline Independence & $\begin{aligned}- & 13.997 \\
& (5.144)^{* * *}\end{aligned}$ & $\begin{array}{l}-0.966 \\
(0.015)^{* * *}\end{array}$ & $\begin{array}{l}-13.758 \\
(3.373)^{* * *}\end{array}$ & $\begin{array}{c}-0.105 \\
(0.376)\end{array}$ \\
\hline Priming independence & $\begin{array}{l}11.242 \\
(6.071)^{*}\end{array}$ & $\begin{array}{c}0.988 \\
(0.005)^{* * *}\end{array}$ & $\begin{array}{l}12.189 \\
(4.251)^{\text {*** }}\end{array}$ & $\begin{array}{c}-0.045 \\
(0.401)\end{array}$ \\
\hline Upstream & $\begin{array}{l}8.407 \\
(3.173)^{* *}\end{array}$ & $\begin{array}{c}0.219 \\
(0.125)^{*}\end{array}$ & $\begin{array}{c}3.981 \\
(2.427)\end{array}$ & $\begin{array}{c}0.164 \\
(0.123)\end{array}$ \\
\hline Number of Obs & 63 & 63 & 78 & 63 \\
\hline (Pseudo) R-squared & 0.189 & 0.103 & 0.079 & 0.04 \\
\hline
\end{tabular}

Note: Priming is a dummy equal to 1 if a participant is in the Information, Public and Punishment treatment, 0 if she is in the Private treatment. Independence is a dummy equal to 1 if the respondent mentioned independence among the 3 most important qualities to teach a child. Community dummy equal to 1 for the upstream community and to 0 for the downstream community. Marginal Effects reported for discrete change of dummy variable from 0 to 1 . Robust standard errors.

* Significant at $10 \%$.

** Significant at $5 \%$

*** Significant at $1 \%$.

Table 10

Regression of contributions on the priming dummy, being in the top 2 deciles in terms of community work done, individualism proxy, and interaction between priming and community work/individualism proxy.

\begin{tabular}{lc}
\hline & (1) Contribution (Bolivianos) \\
\hline Priming & $-5.539^{*}$ \\
& $(4.042)$ \\
Community work & 22.209 \\
& $(7.933)^{* * *}$ \\
Priming community work & -7.526 \\
& $(9.839)$ \\
Independence & -22.791 \\
& $(7.933)^{* * *}$ \\
Priming independence & 20.788 \\
& $(8.495)^{* *}$ \\
Upstream & 9.511 \\
& $(2.874)^{* * *}$ \\
Number of Obs & 63 \\
R-squared & 0.359 \\
\hline
\end{tabular}

Note: Community work is a dummy equal to 1 if participant is in the top 2 deciles of the distribution of days of community work done over the past 12 months. Independence is a dummy equal to 1 if the respondent mentioned independence among the 3 most important qualities to teach a child. Community dummy equal to 1 for the upstream community and to 0 for the downstream community. Marginal Effects reported for discrete change of dummy variable from 0 to 1 . Robust standard errors.

$$
\begin{aligned}
& * \text { Significant at } 10 \% . \\
& * * \text { Significant at } 5 \% .
\end{aligned}
$$$$
\text { *** Significant at } 1 \%
$$

punishment occurs around 25 Bolivianos, i.e. the contribution amount at which Player 1s would go home with the same winnings as Player 2s (Fig. 4).

The evidence presented here, although not conclusive, supports the idea that general social preferences, rather than specific norms concerning the environment, are at work in the experimental setting. This speaks in favor of the generalizability of the results beyond the specific intervention conducted in this study.

\section{Conclusions}

This study uses an artefactual field experiment centered on a reforestation project to analyze social values for CPR conservation. Focusing attention on the social norm increases altruistic choices of selfish individuals. The opposite holds among participants with high valuation of the common good. The results from dyadic regressions suggest that motivation crowding occurs through the effect of external incentives on social image. Experimental results, though of limited statistical significance due to the small sample, are nonetheless valuable and justify a series of considerations and avenues for further enquiry.

The study identifies factors correlated with contributions to a community project. These factors proxy civic engagement and altruism in general, rather than environmental valuation in particular. This makes the findings from this study speak both to the literature on CPR management and to the literature on other-regarding preferences more in general. Research on motivation crowding-out shows how 
Table 11

Dyadic regressions of difference between i and j's contributions/average between $\mathrm{i}$ and $\mathrm{j}$ 's contributions on type of social link between $\mathrm{i}$ and $\mathrm{j}$, and pair's assignment to public group.

\begin{tabular}{|c|c|c|c|c|}
\hline & \multicolumn{2}{|c|}{ Abs $(\mathrm{i}-\mathrm{j}$ contribution $)$} & \multicolumn{2}{|c|}{ Avg(i-j contribution $)$} \\
\hline & $(1)$ & $(2)$ & (3) & (4) \\
\hline i-j same public group & $\begin{array}{c}0.555 \\
(2.460)\end{array}$ & $\begin{array}{c}4.742 \\
(3.334)\end{array}$ & $\begin{array}{l}3.550 \\
(1.574)^{* *}\end{array}$ & $\begin{array}{c}4.787 \\
(3.428)\end{array}$ \\
\hline i-j relatives & $\begin{array}{c}-3.327 \\
(1.717)^{*}\end{array}$ & & $\begin{array}{c}-1.813 \\
(1.461)\end{array}$ & \\
\hline ( $i-j$ same public group) ( $i-j$ relatives $)$ & $\begin{array}{l}10.264 \\
(4.951)^{* *}\end{array}$ & & $\begin{array}{c}-3.592 \\
(3.367)\end{array}$ & \\
\hline $\mathrm{i}-\mathrm{j}$ co-members in associations & & $\begin{array}{l}-1.156 \\
(0.581)^{* *}\end{array}$ & & $\begin{array}{l}-0.820 \\
(0.397)^{* *}\end{array}$ \\
\hline ( $\mathrm{i}-\mathrm{j}$ same public group) ( $\mathrm{i}-\mathrm{j}$ co-members in associations) & & $\begin{array}{c}-1.248 \\
(1.527)\end{array}$ & & $\begin{array}{c}-0.447 \\
(1.230)\end{array}$ \\
\hline Number of Obs & 3906 & 3906 & 3906 & 3906 \\
\hline
\end{tabular}

Note: The dependent variable is the difference between $\mathrm{i}$ and j's contributions in Column 1 and 2 , and the average between $\mathrm{i}$ and $\mathrm{j}$ 's contributions in Column 3 and 4 . "i-j same public group" is a dummy equal to 1 if $i$ and $j$ assigned to the same public treatment group. Columns 1 and 3 control for family relationship between $i$ and $j$ : " $\mathrm{i}-\mathrm{j}$ relatives" is a dummy equal to 1 if $\mathrm{i}$ and $\mathrm{j}$ are relatives. Column 2 and 4 : " $\mathrm{i}-\mathrm{j}$ co-members in associations" is a dummy equal to 1 if $\mathrm{i}$ and $\mathrm{j}$ are members of the same community association(s). Marginal effects reported for discrete change of dummy variable from 0 to 1 . Standard errors adjusted for heteroskedasticity using White's correction in parenthesis.

* Significant at $10 \%$

** Significant at $5 \%$.

*** Significant at $1 \%$.

the introduction of monetary rewards or regulatory sanctions can in some settings reduce pro-social behavior. I claim here that even nonmonetary external incentives, by reducing the signaling value of prosocial decisions, can have similar effects. This finding goes against the claim, based on conventional experiments, that priming leads to crowding-in of pro-social behavior and highlights the risk of generalizing the results from laboratory experiments to infer behavior of actual resource users.

Further empirical work may be worthwhile to test the generalizability of the results. Generalizability should be investigated along two dimensions. First, by conducting similar experiments on a larger scale, the empirical relevance of non-monetary and non-regulatory incentives on motivation crowding could be assessed on a more representative sample. Second, by varying the type of project funded by participants' donation, similar experiments could be used to detect the presence of conservation-specific norms and disentangle their effect from that of norms regulating local public good contributions more in general.

It is commonly believed that regulations and monetary incentives are needed to overcome the incentive problems in common resource use. The crowding-out literature suggests, on the contrary, that external incentives may ultimately be counterproductive. This study finds that the most effective approach may depend on the initial presence of civic values, with external incentives being more effective in settings where intrinsic motivation is low, while solutions generated and owned by the community may be preferable where individuals share civic values and social norms of cooperation.

\section{Acknowledgments}

I thank Brenda Molina, Suri Cabrera, Nardi Santacruz and Miguel Angel Saavedra for research assistance in the field, and the staff of Fundacion Natura Bolivia, especially Paulina Pinto, for hosting this study, and for their advice and logistical support. I also thank Eliana La

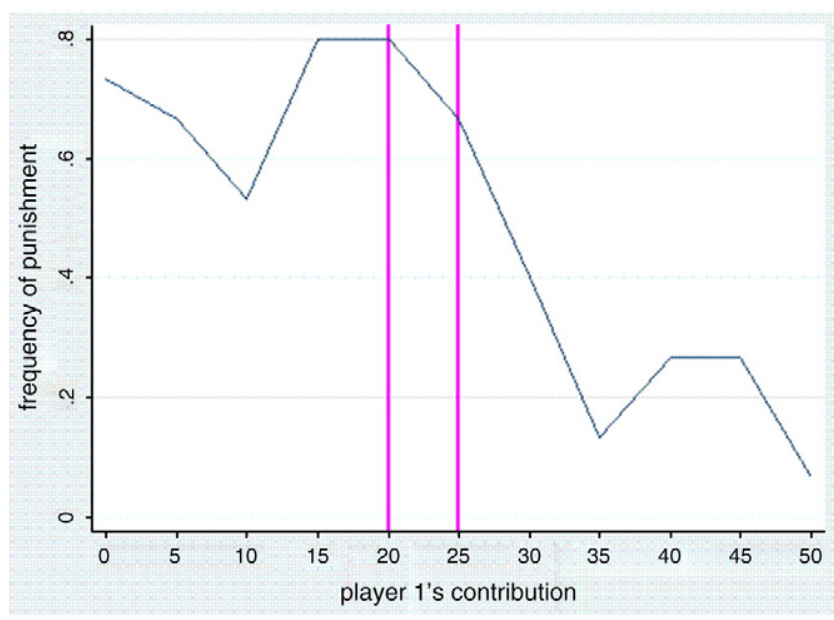

Fig. 4. Punishment percentage for each possible contribution.

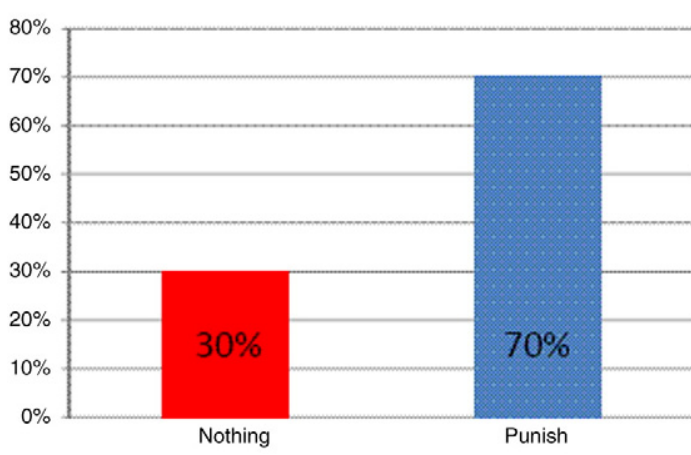

Participants' average decisions for contributions lower than $25 \mathrm{Bs}$

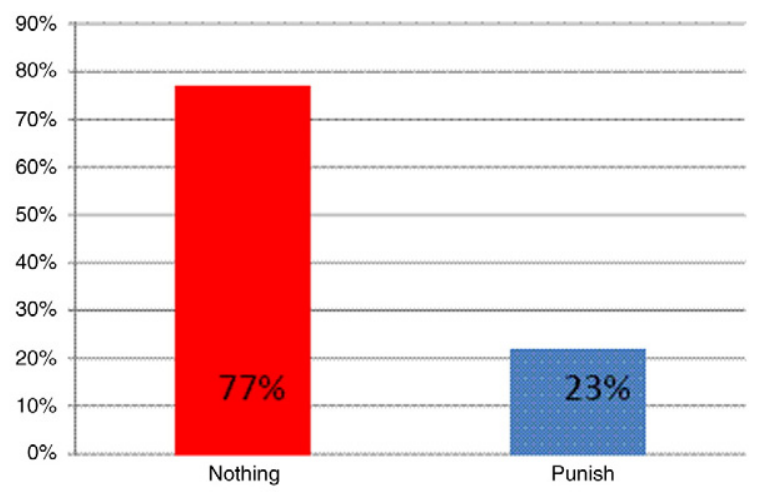

Participants' average decisions for contributions higher than $25 \mathrm{Bs}$

Fig. 3. Punishment decisions for contributions below and above the endowment mean. 
Table 12

Correlation between indicators of individual environmental valuation and contribution amount.

\begin{tabular}{ll}
\hline & (1) Contribution (Bolivianos) \\
\hline Thinks that there are threats to the environment & -0.1990 \\
Has forest on own land & -0.0751 \\
Plants trees on own land & -0.0612 \\
Extracts products from forest & -0.0453 \\
Number of environmental institutions known & 0.0148 \\
\hline
\end{tabular}

Note: Correlation coefficients of row variables with contribution amount.

Ferrara, Juan Camilo Cardenas, Kelsey Jack, Sylvie Lambert, seminar participants at HKS, AMID Summer School and PSE, and two anonymous reviewers for valuable comments that substantially improved this paper. This research benefited from financial support from HKS Sustainability Science Program.

\section{Appendix A. Dyadic Regressions}

Table A1. Dyadic regressions of experimental outcomes on social link and group assignment, controlling for demographic characteristics.

${ }^{*}$ Significant at $10 \%$; ${ }^{* *}$ significant at $5 \%$; ${ }^{* * *}$ significant at $1 \%$.

Note: The dependent variable is the difference between $i$ and $j$ 's contributions in Column 1 and 2, and the average between $i$ and $j$ 's contributions in Column 3 and 4 . " $\mathrm{i}-\mathrm{j}$ same public group" is a dummy equal to 1 if $\mathrm{i}$ and $\mathrm{j}$ assigned to the same public treatment group. Columns 1 and 3 control for family relationship between $i$ and $j:$ " $i-j$ relatives" is a dummy equal to 1 if $i$ and $j$ are relatives. Column 2 and 4 : " $\mathrm{i}-\mathrm{j}$ co-members in associations" is a dummy equal to 1 if $\mathrm{i}$ and $\mathrm{j}$ are members of the same community association(s). Marginal effects reported for discrete change of dummy variable from 0 to 1 . Standard errors adjusted for heteroskedasticity using White's correction in parenthesis.

\begin{tabular}{|c|c|c|c|c|}
\hline & \multicolumn{2}{|c|}{ Abs $(\mathrm{i}-\mathrm{j}$ contribution $)$} & \multicolumn{2}{|c|}{$\operatorname{Avg}(\mathrm{i}-\mathrm{j}$ contribution $)$} \\
\hline & $(1)$ & $(2)$ & (3) & $(4)$ \\
\hline i-j same public group & $\begin{array}{c}-0.191 \\
(2.518)\end{array}$ & $\begin{array}{l}5.607 \\
(2.051)^{* * *}\end{array}$ & $\begin{array}{c}3.151 \\
(1.774)^{*}\end{array}$ & $\begin{array}{l}6.578 \\
(2.023)^{* * *}\end{array}$ \\
\hline $\mathrm{i}-\mathrm{j}$ relatives & $\begin{array}{l}-3.962 \\
(1.639)^{* *}\end{array}$ & & $\begin{array}{l}-2.668 \\
(1.358)^{* *}\end{array}$ & \\
\hline $\begin{array}{l}\text { (i-j same public group) } \\
\quad(\mathrm{i}-\mathrm{j} \text { relatives })\end{array}$ & $\begin{array}{l}11.615 \\
(4.703)^{* *}\end{array}$ & & $\begin{array}{r}-1.567 \\
(3.369)\end{array}$ & \\
\hline $\begin{array}{l}\mathrm{i}-\mathrm{j} \text { co-members in } \\
\text { associations }\end{array}$ & & $\begin{array}{l}-1.223 \\
(0.586)^{* *}\end{array}$ & & $\begin{array}{l}-0.879 \\
(0.385)^{* *}\end{array}$ \\
\hline $\begin{array}{l}\text { ( } \mathrm{i}-\mathrm{j} \text { same public group) } \\
\text { ( } \mathrm{i}-\mathrm{j} \text { co-members in } \\
\text { associations) }\end{array}$ & & -1.864 & & -1.378 \\
\hline & & $(1.456)$ & & $(1.046)$ \\
\hline abs(i's age-j's age) & $\begin{array}{c}-0.046 \\
(0.039)\end{array}$ & $\begin{array}{c}-0.062 \\
(0.038)\end{array}$ & $\begin{array}{c}0.014 \\
(0.043)\end{array}$ & $\begin{array}{c}0.002 \\
(0.043)\end{array}$ \\
\hline i's age + j's age & $\begin{array}{c}-0.017 \\
(0.056)\end{array}$ & $\begin{array}{c}-0.014 \\
(0.056)\end{array}$ & $\begin{array}{c}-0.024 \\
(0.061)\end{array}$ & $\begin{array}{c}-0.023 \\
(0.060)\end{array}$ \\
\hline abs(i female-j female) & -0.158 & -0.201 & -0.016 & -0.061 \\
\hline i female $+\mathrm{j}$ female & $\begin{array}{l}-2.334 \\
(1.275)^{*}\end{array}$ & $\begin{array}{r}-1.937 \\
(1.213)\end{array}$ & $\begin{array}{c}\cdot \\
-0.821 \\
(1.549)\end{array}$ & $\begin{array}{c}-0.534 \\
(1.464)\end{array}$ \\
\hline $\begin{array}{l}\text { abs(i's education-j's } \\
\text { education) }\end{array}$ & $\begin{array}{c}0.142 \\
(0.271)\end{array}$ & $\begin{array}{c}0.246 \\
(0.254)\end{array}$ & $\begin{array}{r}-0.017 \\
(0.231)\end{array}$ & $\begin{array}{c}0.057 \\
(0.234)\end{array}$ \\
\hline $\begin{array}{l}\text { i's education }+\mathrm{j} \text { 's } \\
\text { education }\end{array}$ & $\begin{array}{l}0.083 \\
(0.327)\end{array}$ & $\begin{array}{c}0.076 \\
(0.324)\end{array}$ & $\begin{array}{l}0.369 \\
(0.341)\end{array}$ & $\begin{array}{c}0.365 \\
(0.337)\end{array}$ \\
\hline Number of Obs & 3906 & 3906 & 3906 & 3906 \\
\hline
\end{tabular}

\section{References}

Anderies, J.M., Janssen, M.A., Bousquet, F., Cardenas, J.C., Castillo, D., Lopez, Robert, Tobias, M.C. Vollan, B., Wutich, A., 2011. The challenge of understanding decisions in experimental studies of common pool resource governance. Ecological Economics 70, 1571-1579.

Andreoni, J., Bernheim, D., 2009. Social image and the 50-50 norm: a theoretical and experimental analysis of audience effects. Econometrica 77, 1607-1636.

Baland, J.M., Platteau, J.P., 1996. Halting Degradation of Natural Resources: is there a Role for Rural Communities? Clarendon, Oxford.

Benabou, R., Tirole, J., 2006. Incentives and prosocial behavior. The American Economic Review 96, 1652-1678.

Bohnet, I., Frey, B.S., 1999. Social distance and other-regarding behavior in dictator games: comment. The American Economic Review 89, 335-339.

Brandts, J., Charness, G., 2000. Hot vs. cold: sequential responses and preference stability in experimental games. Experimental Economics 2, 227-238.

Brandts, J., Charness, G., 2009. The Strategy versus the Direct-response Method: A Survey of Experimental Comparisons. http://www.asr.uab.cat/asr/docs/brandts/ strategy_exec.pdf.

Cardenas, J.C., 2000. How do groups solve local commons dilemmas? Lessons from experimental economics in the field. Environment, Development and Sustainability 2 (3-4), 305-322.

Cardenas, J.C., Stranlund, J., Cleve, W., 2000. Local environmental control and institutional crowding-out. World Development 28, 1719-1733.

Casari, M., Cason, T.J., 2009. The strategy method lowers measured trustworthy behavior. Economics Letters 103, 157-159.

Castillo, D., Saysel, A.K., 2005. Simulation of common pool resource field experiments: a behavioral model of collective action. Ecological Economics 55 (3), 420-436.

Charness, G., Gneezy, U., 2009. Incentives to exercise. Econometrica 77, 909-931.

Consejo Municipal de Quirusillas, 2003. Plan de Desarrollo Municipal.

Eckel, C., Grossman, P.J., 1996. Altruism in anonymous dictator games. Games and Economic Behavior 16, 181-191.

Ellingsen, T., Johannesson, M., 2008. Pride and prejudice: the human side of incentive theory. The American Economic Review 98, 990-1008.

Fafchamps, M., Gubert, F., 2007. The formation of risk sharing networks. Journal of Development Economics 83, 326-350.

Falk, A., Kosfeld, M., 2006. The hidden costs of control. The American Economic Review 96, 1611-1630.

Fehr, E., Falk, A., 2002. Psychological foundations of incentives. European Economic Review 46, 687-724.

Fehr, E., Fischbacher, U., 2004. Third party punishment and social norms. Working Paper no.106, Institute for Empirical Research in Economics, University of Zurich.

Fehr, E., Gaechter, S., 2000. Fairness and retaliation: the economics of reciprocity. Working Paper no.40, Institute for Empirical Research in Economics, University of Zurich.

Fehr, E., Hoff, K., Kshetramade, M., 2008. Spite and development. The American Economic Review 98, 494-499.

Frey, B.S., 1994. How intrinsic motivation is crowded out and in. Rationality and Society 6, 334-352.

Frey, Bruno S., Götte, Lorenz, 1999. Does pay motivate volunteers? Institute for empirical research in economics. Working Paper, vol. 7. University of Zurich.

Frey, B.S., Oberholzer-Gee, F., Eichenberger, R., 1996. The old lady visits your backyard: a tale of morals and markets. Journal of Political Economy 104, 1297-1313.

Frey, B., Jegen, R., 2002. Motivation crowding theory. Journal of Economic Surveys 15 589-611.

Frey, Bruno S., Stutzer, Alois, 2006. Environmental morale and motivation. Working Paper, vol. 17. Center for Research in Economics, Management and Arts (CREMA).

Gneezy, U., Rustichini, A., 2000. Pay enough or don't pay at all. Quarterly Journal of Economics 115, 791-810.

Gustavsson, G., 2008. What Individualism Is and Is Not, or The Ideals of Pippi Longstocking and Lisa Simpson. Nordic Political Science Association conference, Tromso.

Hardin, G., 1968. The tragedy of the commons. Science 162, 1243-1248.

Hoffman, E., McCabe, K., Smith, V., 1996. Social distance and other-regarding behavior in dictator games. The American Economic Review 86, 653-660.

Hofstede, G.H., 2001. Culture's Consequences: Comparing Values, Behaviors, Institutions, and Organizations across Nations. Sage Publications, Thousand Oaks, Calif.

Instituto Nacional de Estatistica, 2001. Censo Nacional Poblacion y Vivienda. Republic of Bolivia.

Krupka, E.L., Weber, R.A., 2009. The focusing and informational effect of norms on prosocial behavior. Journal of Economic Psychology 30, 307-320.

Krupka, E.L., Weber, R.A., 2008. Identifying social norms using coordination games: why does dictator game sharing vary? IZA Discussion Paper No. 3860.

Markus, H., Kitayama, S., 1991. Culture and the self: implications for cognition, emotion, and motivation. Psychological Review 98, 224-253.

Ostmann, A., Wojtyniak, B., Beckenkamp, M., 1997. Control and sanctions may destroy commons. Experimental Results and Some Microanalytic Explications. : ISMW Working Paper, vol. 7. University of Karlsruhe.

Ostrom, E., 1990. Governing the Commons: The Evolution of Institutions for Collective Action. Cambridge University Press, New York.

Ostrom, E. 2006. Understanding Institutional Diversity. Princeton University Press, Princeton.

Ostrom, E., Walker, J.M., 1991. Communication in a commons: cooperation without external enforcement. In: Palfrey, T.R. (Ed.), Laboratory Research in Political Economy. University of Michigan Press, Ann Arbor, pp. 287-322.

Ostrom, E., Walker, J.M., Gardner, R., 1992. Covenants with and without a sword: self-governance is possible. American Political Science Review 86, 404-417.

Oxoby, R.J., McLeish, K., 2004. Sequential decision and strategy vector methods in ultimatum bargaining: evidence on the strength of other-regarding behavior. Economics Letters 84, 399-405. 
Rodriguez-Sickert, C., Guzman, R.A., Cardenas, J.C., 2008. Institutions influence preferences: evidence from a common pool resource experiment. Journal of Economic Behavior \& Organization 67, 215-227.

Roth, A.E., 1985. Toward a Focal-Point Theory of Bargaining. Game-Theoretic Models of Bargaining. Cambridge University Press, In.

Titmuss, R.M., 1970. The Gift Relationship: From Human Blood to Social Policy. George Allen and Unwin, London.
Vatn, A., 2006. Resource regimes and cooperation. Land Use Policy 24 (4), 624-632. Vollan, B., 2008. Socio-ecological explanations for crowding-out effects from economic field experiments in Southern Africa. Ecological Economics 67, 560-573.

Vyrastekova, J., van Soest, D., 2003. Centralized common-pool management and local community participation. Land Economics 79, 500-514.

Wade, R., 1986. The Management of Common Property Resources Collective Action as an Alternative to Privatization or State Regulation. 